\title{
Analisis Stabilitas Sistem Tenaga Listrik dengan Automatic Generation Control (AGC) Dua Area menggunakan Metode Fuzzy Logic Controller
}

\author{
Made Dwi Noviantara ${ }^{1}$, I Nengah Suweden ${ }^{2}$, I Made Mataram ${ }^{3}$
}

\begin{abstract}
The power system must be able to service the load in a sustainable manner with good service quality, such as constant stress and frequency, and quickly stabilize when subjected to load changes. When the system changes, the generator control automatically changes the frequency of its optimal value. This scheme is called AGC. To keep the frequency in a stable state, it needs a frequency control system. Currently developed controls with fuzzy logic method. The simulation is performed using 5 membership functions and gives 0.1 pu loading using MATLAB-Simulink software. The simulation is performed to compare the output of the frequency response in the overshoot state and the settling time generated using a Fuzzy logic controller with PID controller. the results of the analysis obtained comparison frequency output response with fuzzy logic controller produces better performance and faster than PID controller. results seen from frequency response output and stability time.
\end{abstract}

Intisari-Sistem tenaga listrik harus mampu melayani beban secara kontinyu dengan kualitas pelayanan yang baik, seperti tegangan dan frekuensi yang konstan, cepat stabil bila mengalami perubahan beban. Ketika sistem mengalami peubahan setiap saat, generator control secara otomatis untuk mengubah frekuensi kenilai optimalnya. Skema ini disebut dengan AGC. Untuk mempertahankan frekuensi dalam keadaan stabil, maka diperlukan sistem pengotrolan frekuensi. Saat ini dikembangkan pengotrolan dengan metode logika fuzzy. Simulasi dilakukan dengan menggunakan 5 fungsi keanggotaan dan memberikan pembebanan sebesar $0,1 \mathrm{pu}$, menggunakan software MATLAB-Simulink. Simulasi dilakukan untuk membandingkan output respon frekuensi dalam keadaan overshoot dan settling time yang dihasilkan menggunakan Fuzzy logic controller dengan PID controller. Dari hasil analisis diperoleh perbandingan output respon frekuensi dengan fuzzy logic controller menghasilkan unjuk kerja yang lebih baik dan lebih cepat dibandingkan PID controller. Dapat dilihat dari output respon frekuensi dan waktu kestabilannya.

Kata Kunci-Sistem control, Automatic Generaion Control, Fuzzy Logic Controller, Simulink Matlab

\footnotetext{
${ }^{1}$ Mahasiswa, Program Studi Teknik Elektro Fakultas Teknik Univesitas Udayana, Jln. Taman Giri, Nusa dua, Kuta Selatan, Badung 08361 INDONESIA (tlp:081338980913; e-mail: dwiantara100@yahoo.co.id)

${ }^{3}$ Dosen, Program Studi Teknik Elektro Fakultas Teknik Universitas Udayana, Jln. Jalan Kampus Bukit Jimbaran 80361 INDONESIA (telp: 0361-703315; fax: 0361-4321; e-mail: Suwede.nengah@gmail.com, mataram@unud.ac.id)
}

\section{Pendahuluan}

Stabilitas sistem tenaga listrik merupakan bagian yang perlu untuk dijaga dalam operasi sisntem tenaga listrik, karena sangat berpengaruh pada semua sistem. Banyak hal yang mempengaruhi stabilitas sistem tenaga listrik, salah satunya adalah beban dinamik. Kestabilan dinamik didefinisikan sebagai kestabilan sistem tenaga listrik akibat perubahan beban kecil yang berlangsung terus menerus [1].

Sistem tenaga listrik harus mampu melayani beban secara kontinyu dengan kualitas pelayanan yang baik seperti tegangan dan frekuensi yang konstan dan cepat stabil bila mengalami perubahan beban. Untuk tetap pada batas-batas stabilitas suatu sistem tenaga listrik perlu ada sistem control yang sering disebut control power system. Pada operasi sistem tenaga listrik daya yang dibangkitkan harus sama dengan beban sistem. Maka dalam mempertahankan frekuensi agar tetap pada batas toleransi yang diijinkan adalah $\pm 2 \%$ dari nominal frekuensi $50 \mathrm{~Hz}$ [2].

Penyesuaian daya aktif ini dilakukan dengan menambah atau mengurangi jumlah energi primer (bahan bakar) dan dilakukan pada governor sesuai kebutuhan beban. Governor yang digunakan pada setiap unit generator pembangkit listrik berfungsi sebagai pengaturan jumlah bahan bakar yang masuk ke ruang pembakaran. Hasil pembakaran digunakan sebagai pemutar turbin. Pengaturan putaran turbin dapat menjaga kestablian sistem keseluruhan terhadap adanya variasi beban atau gangguan sistem. Pengaturan putaran turbin sejak turbin dalam kondisi mulai bergerak hingga turbin dalam kondisi steady state dilakukan pula oleh governor. Oleh karena itu, akibat dari frekuensi yang terus menerus berubah sesuai dengan perubahan beban maka diperlukan sistem pengaturan frekuensi dengan menggunakan AGC ( Automatic Generation Control).

Berbagai usaha dan metode telah digunakan oleh para ahli untuk menjaga kestabilan khususnya terkait dengan masalah perubahan frekuensi yang tergantung kebutuhan beban listrik yang selalu berubah dari waktu ke waktu. Berbagai usaha ini dimulai dari desain kontroler metode konvensional dalam Automatic Generation Control. Penggunaan metode konvensional pada Automatic Generation Control dapat menambah kontrol $\mathrm{P}$ (proposional), I (integral), dan D (derivactive) dalam sistem. Berkembangnya pemodelan modern terdapat metode kecerdasan buatan, metode ini meliputi fuzzy logic, neural network, genetic algorithm, dan lain sebagainya [3]. fuzzy logic dipilih sebagai metode untuk menganalisis stabilitas sistem tenaga listrik dengan Automatic Generation Control yang bertujuan menampilkan hasil simulasi untuk menjaga variasi frekuensi pada pengoperasian pembangkit listrik, maka unjuk kerja (performance) dari AGC 
dalam sistem tenaga listrik akan disimulasikan dengan menggunakan Matlab.

\section{TINJAUAN PUSTAKA}

\section{A. Kestabilan Sistem Tenaga}

Kestabilan sistem tenaga dapat didefinisikan sebagai sifat dari sistem itu yang memungkinkan mesin-mesin serempak dalam sistem tersebut untuk memberikan reaksinya terhadap suatu gangguan pada keadaan kerja yang normal, serta balik kembali ke keadaan semula bila keadaan menjadi normal kembali [4].

\section{B. Automatic Generation Control Interkonesi Dua Area}

Sistem interkoneksi dua area pada dasarnya merupakan perluasan interkoneksi satu generator dengan generator lain yang disebut dengan sinkronisasi.

Pada automatic generation control dua area dihubungkan dengan sebuah reaktansi tie line (saluran penghantar) $X_{\text {tie }}$. Pada sistem interkoneksi dua area perubahan frekuensi terkendalikan dengan cara yang sama, namun tergantung pada perubahan beban $\Delta P_{L}$ [5]. Gambar 1 merupakan implementasi automatic generation control (AGC) dua area.

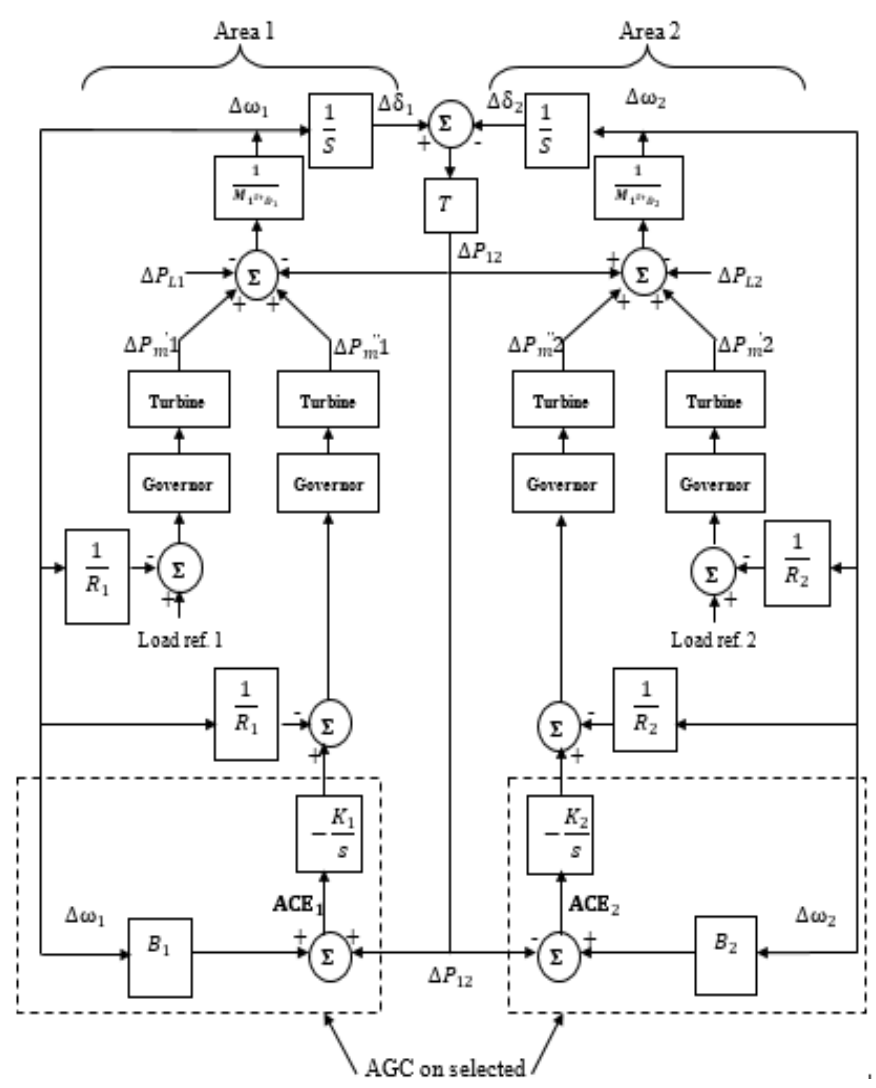

Gambar 1: Diagram blok sistem dua area dengan AGC [5]

Perubahan frekuensi dirumuskan sebagai berikut [5]:

$$
\Delta f=\Delta \omega_{1}=\Delta \omega_{2}=\frac{-\Delta P_{L}}{\left(1 / R_{1}+1 / R_{2}\right)+\left(\mathrm{D}_{1}+\mathrm{D}_{2}\right)}
$$

Pertimbangan nilai steady state setelah kenaikan beban area 1 oleh $\Delta P_{L}$, untuk area 1 :

$$
\Delta P_{m 1}-\Delta P_{12}-\Delta P_{L 1}=\Delta f D_{1}
$$

untuk area 2 :

$$
\Delta P_{m 2}+\Delta P_{12}=\Delta f D_{2}
$$

Perubahan daya mekanik area 1 dan area 2 tergantung pada regulasi, yaitu :

$$
\Delta P_{m 1}=-\frac{\Delta f}{R_{1}} \quad \text { dan } \quad \Delta P_{m 2}=-\frac{\Delta f}{R_{2}}
$$

Hasil subtitusi persamaan (2) kedalam persamaan (3), maka diperoleh :

$$
\begin{aligned}
& \Delta f\left(\frac{1}{R_{1}}+\mathrm{D}_{1}\right)=-\Delta P_{12}-\Delta P_{L 1} \\
& \quad \text { dan } \\
& \Delta f\left(\frac{1}{R_{1}}+\mathrm{D}_{1}\right)=\Delta P_{12}
\end{aligned}
$$

Sehingga penyelesaian persamaan (5) dan (6), diperoleh :

$$
\Delta f=\frac{-\Delta P_{L 1}}{\left(1 / R_{1}+\mathrm{D}_{1}\right)+\left(1 / R_{2}+\mathrm{D}_{2}\right)}=\frac{-\Delta P_{L 1}}{\beta_{1}+\beta_{2}}
$$

dan

$$
\Delta P_{12}=\frac{-\Delta P_{L 1}\left(1 / R_{2}+\mathrm{D}_{2}\right)}{\left(1 / R_{1}+\mathrm{D}_{1}\right)+\left(1 / R_{2}+\mathrm{D}_{2}\right)}=\frac{-\Delta P_{L 1} \beta_{2}}{\beta_{1}+\beta_{2}}
$$

Sinyal kontrol perubahan beban $\left(\Delta P_{L}\right)$ mempengaruhi penyimpangan aliran daya pada area 1 dan penyimpangan frekuensi yang disebut dengan Area Control Error [6]:

$$
A C E=\Delta P_{21}+\left(\frac{1}{R_{1}}+D_{1}\right) \Delta f
$$

Dengan penambahan beban area 1 sebesar $\Delta P_{L 1}$, maka frekuensi menurun pada kedua area dan aliran daya di saluran $\left(\Delta P_{12}\right)$. Perubahan daya dari area 2 ke area 1 bernilai negative, terjadi aliran daya dari area 2 menuju area 1 .

\section{Sitem Pengendalian Daya Aktif dan Frekuensi}

Daya aktif memiliki hubungan dengan nilai frekuensi dalam suatu sistem tenga listrik, sedangkan beban sistem berupa daya aktif selalu berubah dari waktu ke waktu. Untuk mempertahankan frekuensi dalam batas toleransi yang diijinkan, dalam penyediaan daya aktif dalam sistem harus sesuai dengan beban daya aktif yang dibutuhkan. Secara tidak langsung daya aktif pengaturan daya aktif ini dilakukan dengan cara mengatur besarnya kopel penggerak generator [7].

\section{Model Governor}

Governor berfungsi menjaga putaran pada generator agar berada dalam batas tolerasnsi $50 \mathrm{~Hz}$. Untuk model matematis suatu governor dapat dituliskan menjadi [8] :

$\Delta P_{g}(s)=\Delta P_{r e f}(s)-\frac{1}{R} \Delta \omega(s)$

$\Delta P_{g} \quad$ : daya output governor (Watt)

$\Delta P_{\text {ref }} \quad$ : daya refrensi/acuan (Watt)

$\mathrm{R} \quad$ : speed regulation (berkisar 5-6 persen) 
Daya output governor $\Delta P_{g}$ tersebut diubah dari penguat hidrolik ke sinyal input posisi katup (valve) $\Delta P_{V}$, sehingga hubungan antara keduanya menjadi [8]:

$\Delta P_{V}(s)=\frac{1}{1+T_{g}} \Delta P_{g}(s)$

Persamaan di atas dengan $\tau_{g}$ merupakan konstanta waktu governor. Sehingga persamaan (10) dan (11) dapat digambarkan dalam bentuk diagram blok pada Gambar 2 :

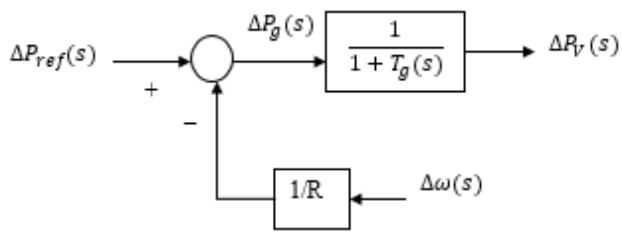

Gambar 2: Diagram blok model governor [8]

\section{E. Model Penggerak Mula}

Pemodelan penggerak mula dalam hal ini sebagai contoh yaitu turbin uap adalah melihat hubungan antara daya mekanik $\Delta P_{m}$ dan perubahan posisi dari katup (valve) $\Delta P_{V}$. Model matematis turbin dapat dituliskan sebagai berikut [9]:

$$
G_{T}(s)=\frac{\Delta P_{M(s)}}{\Delta P_{V(s)}}=\frac{1}{1+T_{T}(s)}
$$

Diagram blok berdasarkan persamaan di atas, yaitu :

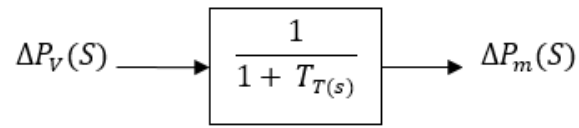

Gambar 3: Diagram blok model penggerak mula/ turbin [9]

\section{F. Model Generator}

Generator merupakan pembangkit tenaga listrik yang mengubah energi mekanis sebagai input menjadi energi listrik sebagai output. Model matematis dapat dituliskan dalam persamaan berikut [9]:

$$
\Delta \omega(s)=\frac{1}{2 H_{s}}\left[\Delta P_{m}(s)-\Delta P_{e}(s)\right]
$$

Ketrangan :

$\Delta \omega(s)=$ Perubahan kecepatan $(\mathrm{rad} / \mathrm{s})$

$H \quad=$ Konstanta inersia

$\Delta P_{m}(s)=$ Perubahan daya mekanik (Watt)

$\Delta P_{e}(s)=$ Perubahan daya akibat perubahan beban (Watt)

Gambar pemodelan generator dan beban dapat dilihat pada Gambar 4.

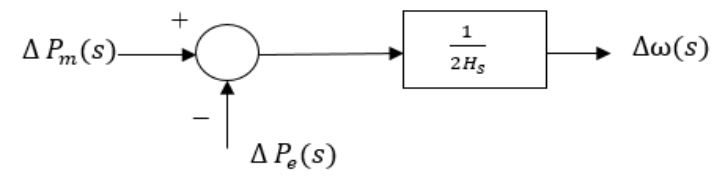

Gambar 4: Diagram blok model generator [9]

\section{G. Model beban}

Made Dwi Noviantara: Analisis Stabiltas Sistem Tenaga ...
Beban pada sistem tenaga listrik terdiri dari gabungan peralatan listrik yang dipasang pada sistem .Model matematis dari beban dimana komponen $\Delta P_{e}(s)$ merupakan penjumlahan antara komponen frekuensi $(D \Delta \omega)$ dan non-frekuensi $\left(\Delta P_{L}\right)$, seperti pada persamaan berikut [9] :

$$
\Delta P_{e}=\Delta P_{L}+D \Delta_{\omega}
$$

Keterangan :

$\Delta P_{e}=$ Perubahan non-frekuensi

$D \Delta \omega=$ Perubahan frekuensi

$D \quad=$ Konstanta redaman beban

Diagram blok beban dari persamaan di atas dapat dilihat pada Gambar 5.

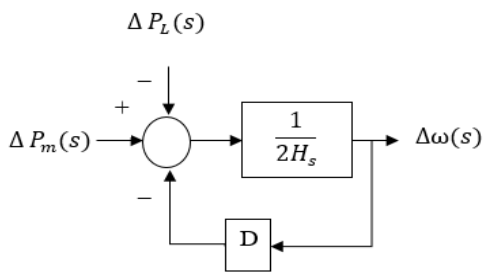

Gambar 5: Diagram blok mobel beban [9]

\section{H. Fuzzy Logic}

Fuzzy adalah metode pemecahan masalah dengan operasi rule base yang dapat memproses sejumlah input dan output yang masuk akal pada sistem nonlinier dan sistem yang kompleks. Metode Mamdani (min-max) fuzzy inference merupakan salah satu teknik yang umum digunakan untuk menangani permasalahan pengendalian [10].

\section{Hasil Penelitian Yang Terkait}

Terdapat beberapa hasil penilitian yang telah dilakukan sebelumnya yang meliki keterkaitan dengan penelitian ini, antara lain :

1. Penelitian yang dilakukan oleh Rishabh Verma pada tahun 2013 menggunakan dua area yaitu area 1 terdiri dari dua pembangkit thermal dan area 2 terdiri dari dua pembangkit hydro yang beroperasi secara paralel. Respon dinamik mempertimbangkan nilai settling time, overshoot, deviasi frekuensi dan daya tie line. Dengan menggunakan fuzzy controller dibandingkan dengan conventional integral, PID controller. Dari analisis kinerja kontroler fuzzy memberikan hasil lebih baik diantara semua controller pembandingnya.

2. Penelitian yang dilakukan oleh Charitha Reddy pada tahun 2017 menganalisis Automatic Generation Control (AGC) memastikan frekuensi dan daya tie-line dalam keadaan steady state. Penelitian ini menggunakan tiga area dengan menggunakan pengendalian Active Disturbance Rejection Control (ADRC). Kinerja ADRC dibandingkan dengan PID Controller. Hasil dari ADRC sangat baik dengan low overshoot dan settling time minimum.

3. Penelitian yang dilakukan oleh Gusti Made Ngurah Chisty Aryanata pada tahun 2017 simulasi studi analisis governor sebagail Load Frequency Control

p-ISSN:1693 - 2951; e-ISSN: 2503-2372

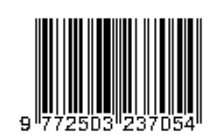


pada PLTG menggunakan Fuzzy Logic Controller dilakukan dengan memberikan empat jenis pembebanan yaitu sebesar $0,1 \mathrm{pu}, 0,2 \mathrm{pu}, 0,3 \mathrm{pu}$, dan 0,4 pu. Simulasi dilakukan untuk membandingkan output respon frekuensi dan waktu kestabilan yang dihasilkan menggunakan fuzzy logic controller. Berdasarkan hasil analisis yang dilakukan membuktikan bahwa governor sebagai load frequency control dengan overshoot yang lebih kecil dan settling time minimum dibandingkan PI controller.

\section{METODELOGI}

Penelitian ini dilakukan di Program Studi Teknik Elektro Fakultas Teknik Universitas Udayana Kampus Sudirman Denpasar, Proses penelitian ini dilakukan mulai bulan Juni tahun 2017. Adapun data yang digunakan diperoleh dari paper oleh Charitha Reddy yang berjudul Automatic Generation Control of Multi-area power System using Active Disturbance Rejection Control. Data yang diperlukan untuk penelitian ini dapat dilihat pada Tabel I sebagai berikut.

TABEL I

PARAMETER VARIABEL NILAI INPUT

\begin{tabular}{|c|l|c|}
\hline No. & \multicolumn{1}{|c|}{ Spesipikasi } & Nilai \\
\hline 1 & Governor Gain $\left(K_{g 1}\right)$ & 1 \\
\hline 2 & Governor Gain $\left(K_{g 2}\right)$ & $0,1 \mathrm{sec}$ \\
\hline 3 & Governor time constant $\left(T_{g 1}\right)$ & $0,2 \mathrm{sec}$ \\
\hline 4 & Governor time constant $\left(T_{g 2}\right)$ & 1 \\
\hline 5 & Turbine Gain $\left(K_{T 1}\right)$ & 0,5 \\
\hline 6 & Turbine Gain $\left(K_{T 2}\right)$ & $0,4 \mathrm{sec}$ \\
\hline 7 & Turbine time constant $\left(T_{T 1}\right)$ & $0,4 \mathrm{sec}$ \\
\hline 8 & Turbine time constant $\left(T_{T 2}\right)$ & $5 \mathrm{sec}$ \\
\hline 9 & Governor Inertia Constant $\left(H_{1}\right)$ & $5 \mathrm{sec}$ \\
\hline 10 & Governor Inertia Constant $\left(H_{2}\right)$ & $1,25 \mathrm{p} . \mathrm{u}$ \\
\hline 11 & Frequency Sensitive Factor $\left(D_{1}\right)$ & $1,25 \mathrm{p} . \mathrm{u}$ \\
\hline 12 & Frequency Sensitive Factor $\left(D_{2}\right)$ & $0,1 \mathrm{p} . \mathrm{u}$ \\
\hline 13 & Change in load $\left(\Delta P_{L 1}\right)$ & $0,1 \mathrm{p} . \mathrm{u}$ \\
\hline 14 & Change in load $\left(\Delta P_{L 2}\right)$ & $0,05 \mathrm{p} . \mathrm{u}$ \\
\hline 15 & Speed regulation $\left(R_{1}\right)$ & $0,05 \mathrm{p} . \mathrm{u}$ \\
\hline 16 & Speed regulation $\left(R_{2}\right)$ & $22.6 \mathrm{p} . \mathrm{u}$ \\
\hline 17 & Synchronizing coefficient $\left(P_{2}\right)$ & \\
\hline & & \\
\hline
\end{tabular}

Data yang kemudian dianalisis dengan prosedur membuat pemodelan Automatic Generation Control (AGC) dua area. Simulasi dilakukan dengan menggunakan Matlab. Simulasi dilakukan dengan menggunakan dua metode yaitu dengan Fuzzy Logic Controller dengan PID Controller. Dari kedua hasil simulasi dibandingkan untuk mengetahui output respon frekuensi yang lebih baik. Alur analisis dapat dilihat pada Gambar 6.



Gambar 6: Alur analisis

\section{IV.HASIL DAN PEMBAHASAN}

A. Pemodelan Automatic Generation Control Pada Sistem Tenaga Listrik Dua Area Menggunakan Metode dengan PID Controller.

Simulasi dilakukan dengan memasukan nilai variabel input model matematis yaitu parameter governor termasuk speed regulation, penggerak mula (prime mover), generator dan beban (load). Hasil simulasi Automatic Generation Control (AGC) dua area pada sistem tenaga listrik menggunakan metode dengan PID yang sudah dimasukan nilai variabel input sesua dengan data yang ada. 


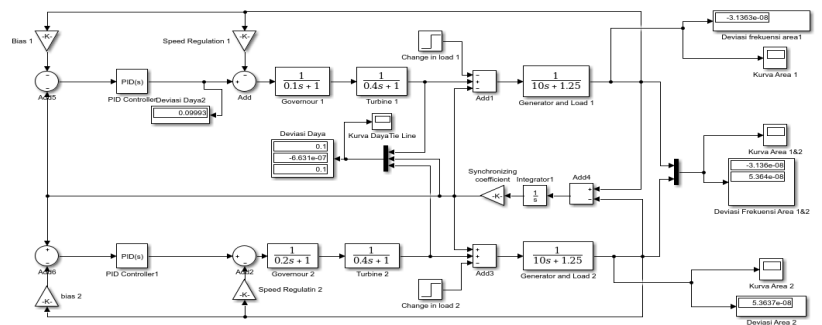

Gambar 7: Hasil simulasi automatic generation control (AGC) dua area pada sistem tenaga listrik menggunakan metode konvensional dengan PID controller

Berdasarkan data yang diperoleh dari Automatic Generation Control (AGC) dua Area pada Sistem Tenaga Listrik menggunakan Metode PID Controller.

1. Kurva Hasil Simulasi Area 1

Kurva hasil simulasi area 1 menghasilkan deviasi frekuensi saat keadaan overshoot yaitu $-3.86 \times 10^{-3} p u$ dan waktu penempatan (settling time) yaitu 20.5 detik.



2. Kurva Hasil Simulasi Area 2

Kurva hasil simulasi area 2 menghasilkan deviasi frekuensi saat keadaan overshoot yaitu $-4.3 \times 10^{-3} p u$ dan waktu penempatan (settling time) yaitu 20.5 detik.

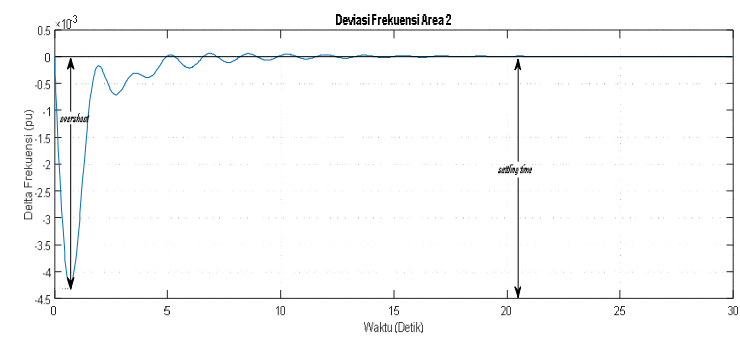

Gambar 9: Kurva hasil simulasi area 2

3. Kurva Hasil Simulasi Daya Tie-Line Area 1

Kurva hasil simulasi daya tie-line area 1 ke area 2 menghasilkan deviasi frekuensi saat keadaan overshoot yaitu $5.6 \times 10^{-3} p u$ dan waktu penempatan (settling time) yaitu 20.1 detik.

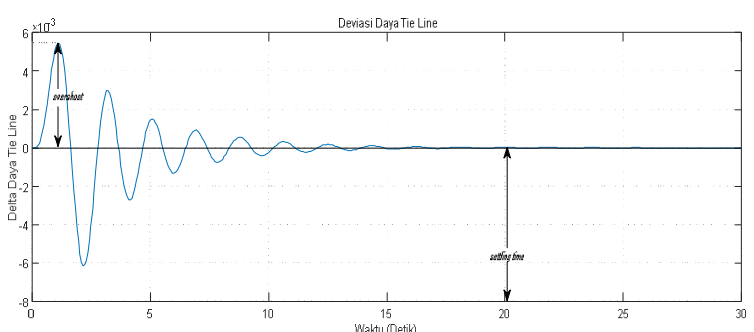

Gambar 10: Kurva hasil simulasi daya tie line

B. Pemodelan Automatic Generation Control Pada Sistem Tenaga Listrik Dua Area Menggunakan Metode Fuzzy Logic Controller.

Untuk dapat membuat pemodelan Automatic Generation Control (AGC) menggunakan fuzzy logic controller, data penelitian yang digunakan adalah nilai area control error (ACE) sebagai input 1 dan deviasi area control error $(\triangle \mathrm{ACE})$ sebagai input 2, dan nilai frekuensi yang ditoleransi sebagai output. Dapat dibentuk membership function masing-masing iput dan output.

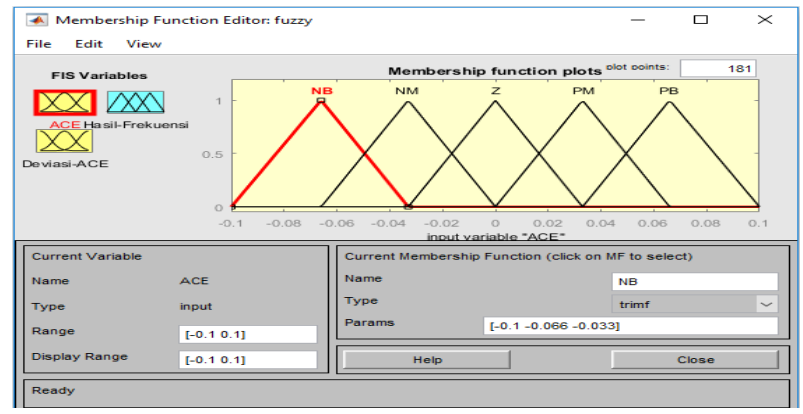

Gambar 11: Membership function input 1



Gambar 12: Membership function input 2

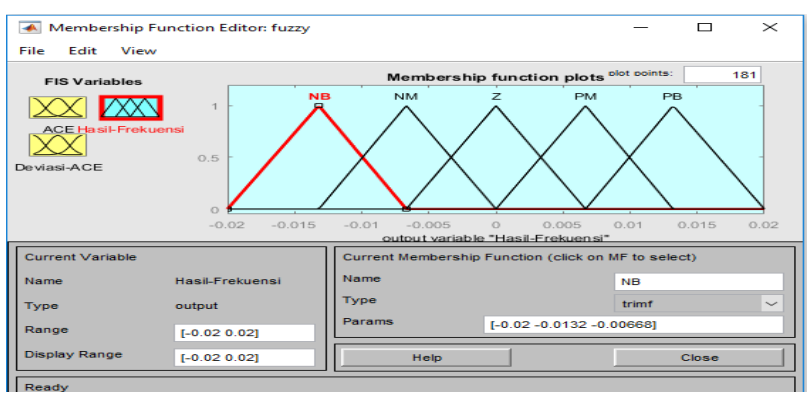

Gambar 13: Membership function ouput

p-ISSN:1693 - 2951; e-ISSN: 2503-2372

Made Dwi Noviantara: Analisis Stabiltas Sistem Tenaga ...

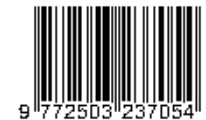


Pada penelitian ini digunakan 5 membership function, maka input area control error, deviasi area control error dan nilai frekuensi. Dari 5 membership function mengasilkan 25 rule base dapat dilihat pada Tabel II.

TABEL II

RULE BASE AUtomatic GENERATION CONTROL MENGGUNAKAN FUZZY LOGIC CONTROLLER

\begin{tabular}{|c|c|c|c|c|c|}
\hline AACE & $\begin{array}{c}\text { Negative } \\
\text { Big }(\mathbf{N B})\end{array}$ & $\begin{array}{c}\text { Negative } \\
\text { Medium } \\
(\mathbf{N M})\end{array}$ & $\begin{array}{c}\text { Zero } \\
(\mathbf{Z E})\end{array}$ & $\begin{array}{c}\text { Positive } \\
\text { Medium } \\
(\boldsymbol{P M})\end{array}$ & $\begin{array}{c}\text { Positive } \\
\text { Big }(\boldsymbol{P B})\end{array}$ \\
\hline $\begin{array}{c}\text { Negative } \\
\text { Big (NB) }\end{array}$ & $N B$ & $N B$ & $N M$ & $N M$ & $Z E$ \\
\hline $\begin{array}{c}\text { Negative } \\
\text { Medium } \\
(\text { NM) }\end{array}$ & $N B$ & $N B$ & $N M$ & $Z E$ & $P M$ \\
\hline $\begin{array}{c}\text { Zero } \\
(\mathbf{Z E})\end{array}$ & $B M$ & $N M$ & $Z E$ & $P M$ & $P M$ \\
\hline $\begin{array}{c}\text { Positive } \\
\text { Medium } \\
(\boldsymbol{P M})\end{array}$ & $N M$ & $Z E$ & $P M$ & $P B$ & $P B$ \\
\hline $\begin{array}{c}\text { Positive } \\
\text { Big (PB) }\end{array}$ & $Z E$ & $P M$ & $P M$ & $P B$ & $P B$ \\
\hline
\end{tabular}

Berikut merupakan Simulink Automatik Generation Control (AGC) dua area menggunakan fuzzy logic controller yang sudah dimasukan variabel input sesuai dengan data diatas dapat dilihat pada Gambar 14.

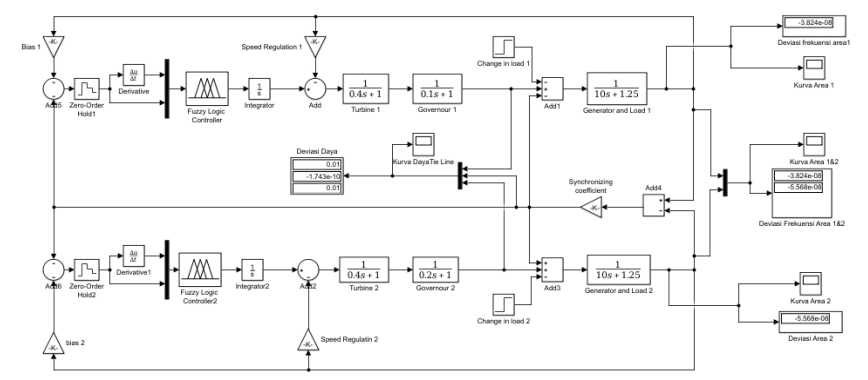

Gambar 14: Hasil simulasi automatic generation control (AGC) dua area pada sistem tenaga listrik menggunakan metode fuzzy logic

Berdasarkan data yang diperoleh dari Automatic Generation Control (AGC) dua area pada sistem tenaga listrik menggunakan metode Fuzzy Logic Controller berikut kurva hasil simulasi.

1. Kurva Hasil Simulasi Area 1

Kurva hasil simulasi area 1 menghasilkan deviasi frekuensi saat keadaan overshoot yaitu $-6 \times 10^{-4} \mathrm{pu}$ dan waktu penempatan (settling time) yaitu 16 detik.

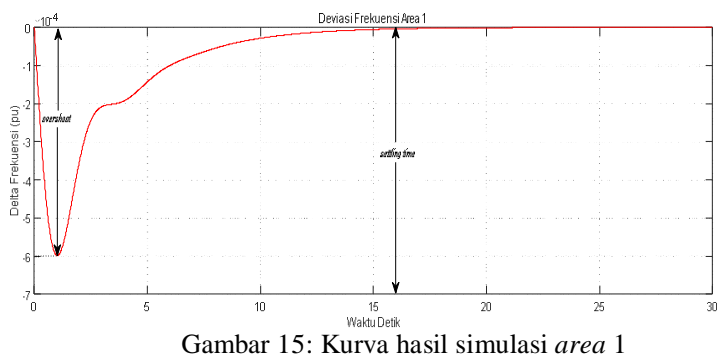

2. Kurva Hasil Simulasi Area 2

Kurva hasil simulasi area 2 menghasilkan deviasi frekuensi saat keadaan overshoot yaitu $-6.4 \times 10^{-4} p u$ dan waktu penempatan (settling time) yaitu 16 detik.



3. Kurva Hasil Simulasi Daya Tie-Line

Kurva hasil simulasi daya tie-line area 1 ke area 2 menghasilkan deviasi frekuensi saat keadaan overshoot yaitu $5.3 \times 10^{-4} \mathrm{pu}$ dan waktu penempatan (settling time) yaitu 5.76 detik.

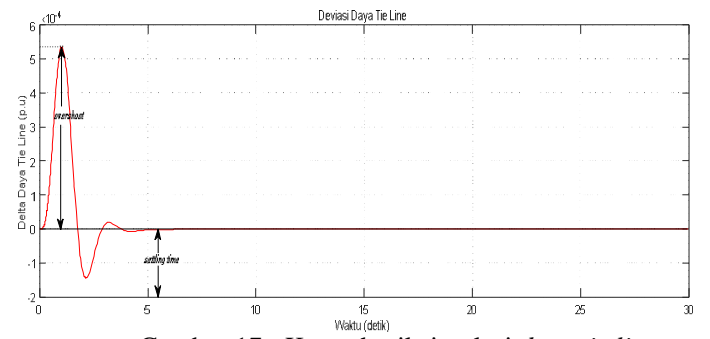

Gambar 17: Kurva hasil simulasi daya tie line

C. Perbandingan Metode PID Controller dengan Fuzzy Logic Controller Area 1.

Perbandingan respon automatic generation control area 1 menggunakan metode PID controller dan metode fuzzy logic controller dapat dilihat pada gambar di bawah ini.

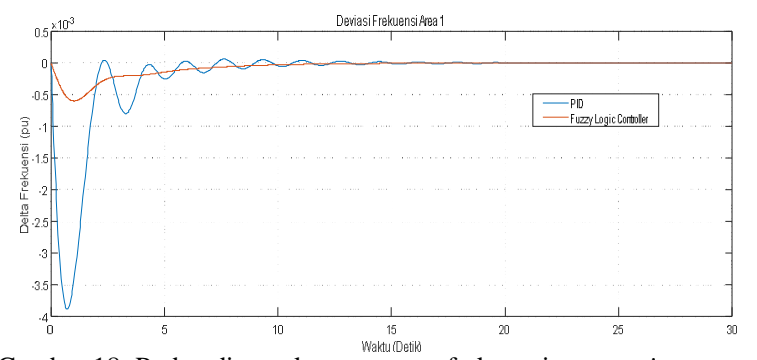

Gambar 18: Perbandingan kurva respon frekuensi automatic generation control (AGC) area 1

Berdarkan hasil simulasi yang ditampilkan pada Gambar 18 diperoleh perbandingan respon frekuensi area 1 yang dapat dilihat pada Tabel III : 
TABEL III

HASIL SIMULASI AREA III

\begin{tabular}{|c|c|c|}
\hline \multirow{2}{*}{ Area 1 } & \multicolumn{2}{|c|}{ Tipe Kontroler } \\
\cline { 2 - 3 } & $\begin{array}{c}\text { Metode Konvensional } \\
\text { PID }\end{array}$ & $\begin{array}{c}\text { Metode Fuzzy Logic } \\
\text { Controller }\end{array}$ \\
\hline Settling time & 20.5 detik & 12 detik \\
\hline $\begin{array}{c}\text { Defiasi } \\
\text { Overshoot }\end{array}$ & $0^{-3} \mathrm{pu}$ & $-0.6 \times 10^{-3} \mathrm{pu}$ \\
\hline
\end{tabular}

Berdasarkan perbandingan pada Tabel III dari analisis stabilitas sistem tenaga listrik automatic generation control dua area menggunakan fuzzy logic controller menghasilkan respon frekuensi yang lebih baik dan cepat dibandingkan dengan menggunakan metode PID controller.

D. Perbandingan Metode PID Controller dengan Fuzzy Logic Controller Area 2.

Perbandingan respon automatic generation control area 2 menggunakan metode PID controller dan metode fuzzy logic controller.



Gambar 19: Perbandingan kurva respon frekuensi automatic generation control (AGC) area 2.

Berdasarkan hasil simulasi yang ditampilkan pada Gambar 19 diperoleh perbandingan respon frekuensi area 2 yang dapat dilihat pada Tabel IV :

TABEL IV

HASIL SIMULASI AREA 2

\begin{tabular}{|c|c|c|}
\hline \multirow{2}{*}{ Daya Tie Line } & \multicolumn{2}{|c|}{ Tipe Kontroler } \\
\cline { 2 - 3 } & $\begin{array}{c}\text { Metode } \\
\text { Konvensional PID }\end{array}$ & $\begin{array}{c}\text { Metode Fuzzy Logic } \\
\text { Controller }\end{array}$ \\
\hline Settling time & 20.1 detik & 3.5 detik \\
\hline $\begin{array}{c}\text { Defiasi } \\
\text { Overshoot }\end{array}$ & $5.6 \times 10^{-3} \mathrm{pu}$ & $0.53 \times 10^{-3} \mathrm{pu}$ \\
\hline
\end{tabular}

Berdasarkan perbandingan pada Tabel I dari analisis stabilitas sistem tenaga listrik automatic generation control menggunakan metode fuzzy logic controller mengasilkan respon frekuensi yang lebih baik dan cepat dibandingkan menggunakan metode PID controller.

E. Perbandingan Metode PID Controller dengan Fuzzy Logic Controller Deviasi Daya Tie-Line.

Made Dwi Noviantara: Analisis Stabiltas Sistem Tenaga ...
Perbandingan respon automatic generation control deviasi daya tie-line area 1 ke area 2 menggunakan metode PID controller dan metode fuzzy logic controller.

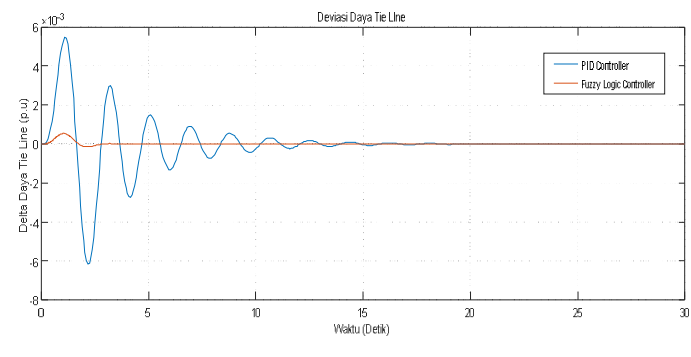

Gambar 20: Kurva hasil simulasi daya tie line

Berdasarkan hasil simulasi yang ditampilkan pada Gambar 20 diperoleh perbandingan respon frekuensi pada daya tie-line area 1 ke area 2 .

TABEL V

HASIL SIMULASI DAYA TIE LINE

\begin{tabular}{|c|c|c|}
\hline \multirow{2}{*}{ Area 2 } & \multicolumn{2}{|c|}{ Tipe Kontroler } \\
\cline { 2 - 3 } & $\begin{array}{c}\text { Metode Konvensional } \\
\text { PID }\end{array}$ & $\begin{array}{c}\text { Metode Fuzzy Logic } \\
\text { Controller }\end{array}$ \\
\hline Settling time & 20.5 detik & 12 detik \\
\hline $\begin{array}{c}\text { Defiasi } \\
\text { Overshoot }\end{array}$ & $-4.3 \times 10^{-3} p u$ & $-0.64 \times 10^{-3} p u$ \\
\hline
\end{tabular}

Berdasarkan perbandingan pada Tabel $\mathrm{V}$ dari hasil analisis stabilitas sistem tenaga listrik automatic generation control menggunakan metode fuzzy logic controller mengasilkan respon frekuensi yang lebih baik dan cepat dibandingkan menggunakan metode PID controller.

\section{KESIMPULAN}

Berdasarkan hasil pembahasan disimpulkan bahwa perbandingan hasil respon frekuensi automatic generation control (AGC) dua area pada sistem tenaga listrik dengan menggunakan metode fuzzy logic controller menghasilkan output respon frekuensi yang lebih baik dari pada menggunakan metode PID controller. Dapat dilihat dari overshoot yang lebih kecil dan settling time yang lebih cepat.

\section{REFERENSI}

[1] Robandi, Imam. Desain System Tenaga Modern. Yogyakarta: ANDI Yogyakarta. 2006.

[2] NN. Aturan Jaringan Sistem Tenaga Listrik Jawa-Madura-Bali. Departemen Energi dan Sumber Daya Mineral. 2007.

[3] Aryanata Gusti Made Ngurah Christy. "Studi Analisis governor sebagai Load Frequency Control pada PLTG menggunakan Fuzzy Logic Controller”. (Skripsi). Denpasar : Universitas Udayana. 2017.

[4] I M A Nrartha, A B Muljono. Pengaruh Power System Stabilizer Pada Sistem Tenaga Listrik Dengan Unit Pembangkit Tersebar. Majalah Ilmiah Teknologi Elektro. Vol.9, No.1. 2010.

[5] Mataram I Made. Perbandingan Penggunaan Jumlah dan Jenis Fungsi Keanggotaan Pada Metode Logika Fuzzy Untuk Pengontrolan Frekuensi Beban. Badung: Universitas Udayana. 2013.

[6] Rishabh Verma, Shalini Pal, Sathans. Fuzzy Gain Scheduled Automatic Generation Control of Two Area Multi Unit Power System. Stdt, Dept 
of Engineering National Institute of Thecnology. Akurukshetra: India. 2013.

[7] Kundur, P. Power System Stability and Control. Toronto:Mcgraw-Hill. 1994.

[8] Saadat, Hadi. Power System Analysis.Tata McGraw-Hill Edition. New Delhi. 2002.

[9] Y.V.L Charitha Reddy, Dr. M.S. Krishnarayalu. Automatic Generation Control of Multi-area Power System using Active Disturbance Rejection Control. International Journal of Enggineering Trens and Technology (IJETT). Vol.43 No.4. (ISSN:2231-5381). 2017.

[10] Mataram I Made. Unjuk Kerja Fuzzy Logic Static Synchrounous Compensator (FLSTATCOM) Untuk Meningkatkan Tegangan Sistem. Majalah Ilmiah Teknologi Elektro. Vol.15, No.1. (ISSN: 1963-2951). 2016. 